\title{
Feasibility, safety, and long-term efficacy of stereotactic radiofrequency ablation for tumors adjacent to the diaphragm in the hepatic dome: a case-control study
}

\author{
Peter Schullian ${ }^{1} \cdot$ Daniel Putzer $^{1} \cdot$ Gregor Laimer $^{1} \cdot$ Elliot Levy $^{2} \cdot$ Reto Bale $^{1}$ \\ Received: 18 July 2019 / Revised: 24 July 2019 / Accepted: 26 July 2019 / Published online: 5 September 2019 \\ (C) The Author(s) 2019
}

\begin{abstract}
Objectives Achievement of adequate treatment margins may be challenging when the target is either difficult to visualize, awkward to access, or situated adjacent to vulnerable structures. Treatment of tumors located close to the diaphragm in the hepatic dome is challenging for percutaneous radiofrequency (RF) ablation for these reasons. The purpose was to assess the feasibility, safety, and clinical outcome of multi-probe stereotactic RF ablation (SRFA) of liver tumors in the subdiaphragmatic area.

Methods Between 2006 and 2018, 177 patients ( 82 HCCs, 6 ICCs, and 89 metastatic tumors) underwent SRFA of 238 tumors abutting the diaphragm in the hepatic dome. For comparison, 177 patients were randomly selected from our database by the R package "MatchIt" for propensity score matching to compare treatment safety and efficacy in this retrospective, single-center study.

Results Median treated tumor size was $2.2 \mathrm{~cm}$ (range 0.5 to $10 \mathrm{~cm}$ ). SRFA was primarily successful for 232/238 (97.5\%) tumors. Five tumors were successfully retreated, resulting in a secondary technical efficacy rate of $99.6 \%$. Local tumor recurrence developed in 21 of 238 tumors (8.8\%). The major ablation complication rate was $10.7 \%$ (22 of 204). Twelve (55\%) of 22 major complications could be successfully treated by the interventional radiologist in the same anesthesia session. There was no significant difference in adverse events or disease control rates between the subdiaphragmatic tumors and matched controls. Conclusions SRFA is a safe and feasible option in the management of difficult-to-treat tumors abutting the diaphragm in the hepatic dome, with similar safety profile compared with matched controls.

Key Points

- RFA was primarily successful for 232/238 (97.5\%) subdiaphragmatic dome tumors. Local tumor recurrence developed in 21 of 238 tumors $(8.8 \%)$.

- The major complication rate directly related to ablation of the hepatic dome tumors was 10.7\% (22 of 204). 12/22 (55\%) of major complications could be successfully treated in the same anesthesia session.

- There was no significant difference in adverse events or disease control rates between the subdiaphragmatic tumors and matched controls.
\end{abstract}

Keywords Radiofrequency ablation $\cdot$ Liver $\cdot$ Neoplasms

Reto Bale

reto.bale@i-med.ac.at

1 Department of Radiology, Section of Interventional Oncology Microinvasive Therapy, Medical University of Innsbruck, Anichstr. 35, 6020 Innsbruck, Austria

2 Radiology and Imaging Sciences, National Institutes of Health, Bethesda, MD, USA

\begin{tabular}{|c|c|}
\hline \multicolumn{2}{|c|}{ Abbreviations } \\
\hline DFS & Disease-free survival \\
\hline $\mathrm{HCC}$ & Hepatocellular carcinoma \\
\hline ICC & Intrahepatic cholangiocarcinoma \\
\hline $\mathrm{IN}$ & Incomplete necrosis \\
\hline LR & Local recurrence \\
\hline OS & Overall survival \\
\hline RF & Radiofrequency \\
\hline SRFA & Stereotactic radiofrequency ablation \\
\hline TACE & Transcatheter arterial chemoembolization \\
\hline
\end{tabular}




\section{Introduction}

RF ablation has been increasingly accepted as a curative alternative to surgical resection in the management of primary or metastatic liver tumors $[1,2]$. The achievement of a sufficient safety margin, i.e., complete coverage of the coagulation zone with a margin of at least $5 \mathrm{~mm}$, is crucial for good local tumor control and clinical outcome [3]. Treatment of subdiaphragmatically located tumors located in the hepatic dome is challenging when the target tumor is difficult to visualize, awkward to access, or situated adjacent to vulnerable structures. Treatment of tumors located close to the diaphragm implies a higher risk of complications such as pneumothorax or diaphragmatic injuries. Several studies reported severe right shoulder pain after treatment of hepatic dome tumors $[4,5]$.

Common strategies include angulated approach sparing the pleura [5] or transthoracic or transpleural access [6-8]. Hydrodissection is another possible protective method in the hepatic dome [9]. In addition, these tumors located posteriorly and superiorly also pose a significant technical challenge for laparoscopic liver resection, demanding special approaches and techniques [10]. There are several studies reporting limited local tumor control in subcapsular locations with conventional RF ablation [11], higher complication rates (mainly bleeding), as well as tumor recurrence [12, 13]. Stereotaxy has proven useful for planning and execution of complex or difficult ablations. Difficult access routes may be specifically facilitated and more precise coverage of the target tumor and safety margin accomplished with frameless stereotactic navigation systems [14].

The purpose of the current study was to assess the feasibility, safety, and clinical outcome of multi-probe SRFA of liver tumors close to the diaphragm and to compare the results with a matched control group. Our hypothesis was that there is no difference in terms of safety and local control for tumors in the hepatic dome vs. non-hepatic dome tumors.

\section{Materials and methods}

\section{Patient cohort and inclusion criteria}

This retrospective, single-center study was approved by the Institutional Review Board. Written informed consent for SFRA was obtained from all patients. All cases were reviewed and treatment plans approved by consensus in multidisciplinary tumor board meetings. Between 2006 and 2018, 891 consecutive patients were treated by SRFA. Seventy-two patients with invasion of the portal vein, extended tumor spread with subsequent palliative intention to treat, or benign liver tumors were excluded (Fig. 1). A total of $177 / 819$ patients with hepatic dome tumors were included. A total of 177 hepatic ablation patients were selected using nearest neighbor propensity score matching by the R package "MatchIt" with sex, age, tumor type, number and size, and liver function as matching variables. The baseline characteristics of the two groups are shown in Table 1.

Exclusion criteria for SRFA were a platelet count of $<50,000 / \mathrm{mm}^{3}$ and prothrombin activity $<50 \%$. Tumor diagnosis was confirmed by classic tumor enhancement pattern on multi-phasic contrast MRI or CT and pathologically validated by needle biopsy during the RF ablation. The hepatic dome was defined as the portion of the liver located close to the diaphragm, accounting for almost one-third of the total liver volume.

\section{Multi-probe stereotactic radiofrequency ablation}

The method of SRFA has been described previously $[15,16]$. Patients under general anesthesia were immobilized on the CT table by a single- (Bluebag, Medical Intelligence) or doublevacuum fixation technique (BodyFix, Medical Intelligence) with paralysis. For image registration, 10-15 optical fiducials, (X-SPOT, Beekley Corporation) were broadly attached to the skin of the thorax and upper abdomen.

A contrast-enhanced planning CT (Siemens SOMATOM Sensation Open, sliding gantry with $82-\mathrm{cm}$ diameter, Siemens AG) was obtained with 3-mm slice thickness in exhalatory phase. To improve image registration, the endotracheal tube (ETT) was transiently disconnected during the planning CT, each stereotactic needle placement, and the final control CT. The pretreatment CT datasets were transferred to the opticalbased navigation system (Stealth Station Treon Plus, Medtronic Inc.). All nodules abutting the diaphragm in the hepatic dome were targeted with an angulated either sub- or intercostal approach avoiding the pleural recess. SRFA probe trajectories were planned using multi-planar and 3D reconstructed images. After automatic registration and a registration accuracy check, 15-G/17.2-cm coaxial needles (Bard Inc.) were advanced through an ATLAS aiming device (Medical Intelligence Inc.) without real-time imaging control. The ATLAS aiming device consists of two joints and a bracket holder with an adjustable concentric aperture for the use of different instruments. It is mounted to a mechanical arm with three joints and six degrees of freedom allowing for precise trajectory alignment. The depth from the aiming device to the target was automatically calculated by the navigation software. In order to achieve complete necrosis of the entire tumor tissue with an appropriate circumferential safety margin, RFA electrodes were aligned to each other with a maximum separation distance of $2 \mathrm{~cm}$. For verification of correct needle placement, a native control CT was performed and fused with the planning CT using the navigation system's image 3D registration algorithm. A 16-G coaxial biopsy sample was obtained in all cases. 17-G RF electrodes (Cool-tip, Medtronic, 25$\mathrm{cm}$ length and $3-\mathrm{cm}$ exposure) were then introduced through 
891 consecutive patients treated with SRFA (2006-2018)

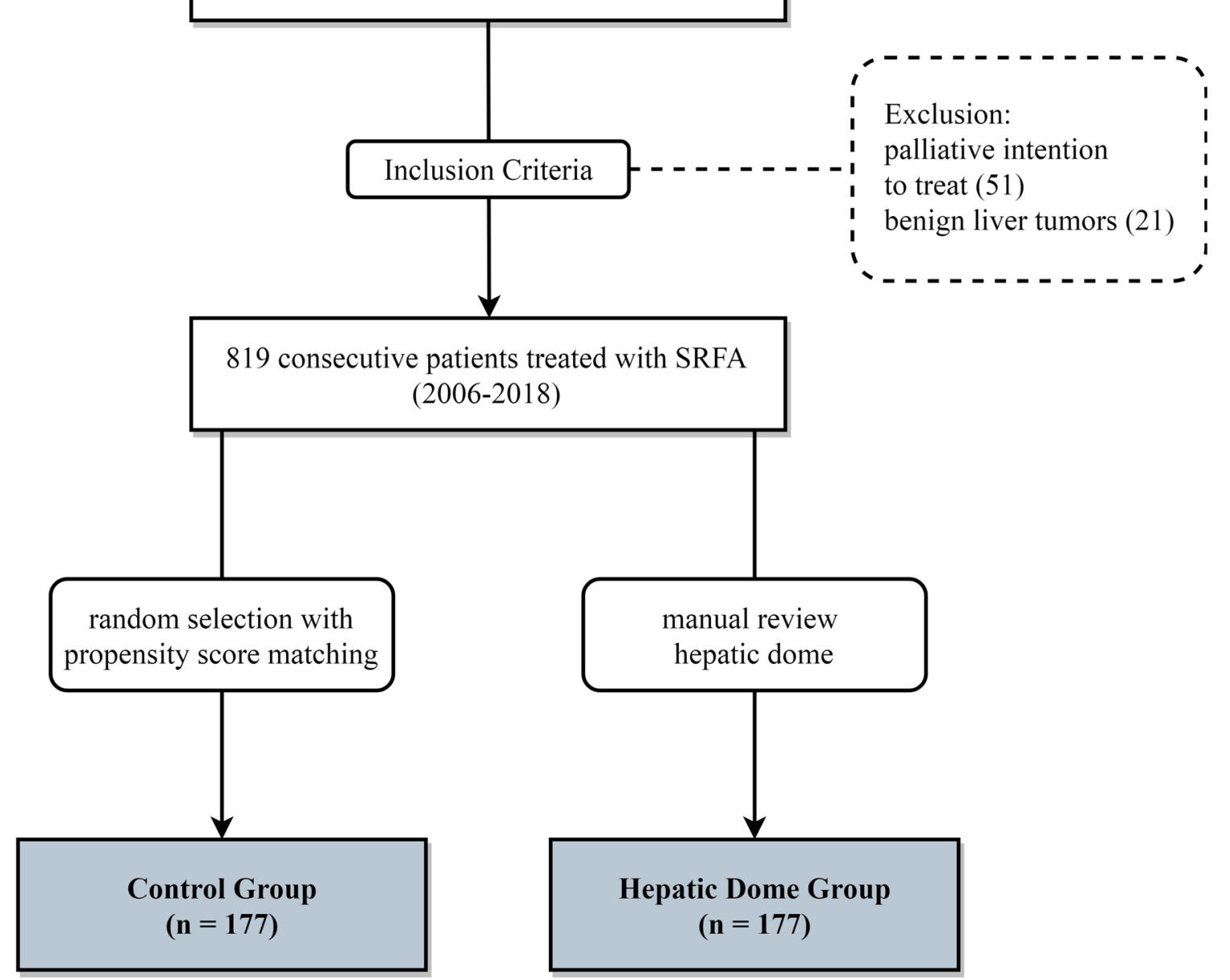

Fig. 1 Flowchart of group assignment

the coaxial needles for serial tumor ablation. RF ablation was carried out using the unipolar Cool-tip_RF generator (Cooltip, Medtronic), including the Cool-tip_RF switching controller. The ablation time for three electrodes (switching control) was 16 min. Finally, an immediate contrast-enhanced CT scan was performed and fused with the planning CT for verification of the ablation size and to exclude possible complications. Needle track ablation was done during repositioning and during final removal of the RF electrodes to prevent bleeding and potential tumor seeding. Example images from multi-probe SRFA in the hepatic dome are shown in Figs. 2 and 3.

The study endpoints of primary and secondary technical efficacy and local recurrence rate (LR) were determined by follow-up contrast-enhanced CT or MR scans performed at 1-month and at 3-month intervals after RF ablation. The imaging results were evaluated by two abdominal radiologists with more than 10 years of experience by consensus (PES and BR). Technical success was defined as sufficiently accurate (deviation $<1 \mathrm{~cm}$ at the needle tip) electrode placement according to predefined plans. Complete ablation was defined as a circumscribed non-enhancing zone within and/or extending beyond the initial tumor borders with a well-defined margin. Appearance of new nodules within or directly adjacent to the ablation zone or to initial tumor was judged to constitute LR. New nodules distant to the ablation zone and/or to initial tumor location were defined as distant tumor recurrence. Primary technical efficacy rate was evaluated per tumor as the absence of residual tumor on 1-month follow-up CT. Secondary technical efficacy rate included tumors that demanded reablation due to residual tumor. Complications were defined according to the Society of Interventional Radiology (SIR) Standards of Practice Committee classification [17]. The secondary study endpoints included disease-free (DFS) and overall survival (OS). In patients with exclusively hepatic dome HCC tumors and accordingly matched controls, survival was calculated from the date of initial stereotactic RF ablation to the date of death attributable to malignancy or other causes (i.e., event) or to the most recent follow-up visit (i.e., censoring). 
Table 1 Patient characteristics of 177 patients undergoing 204 SRFA sessions of 238 nodules in the hepatic dome group and of 177 patients undergoing 281 SRFA sessions of 587 nodules in the control group

\begin{tabular}{lll}
\hline Patient characteristics & Hepatic dome gr. & Control gr. \\
\hline Age, median years (range) & $65(7-87)$ & $64(25-82)$ \\
Sex (female/male), $n(\%)$ & $48 / 129(27.1 / 72.9)$ & $48 / 129(27.1 / 72.9)$ \\
Tumor type, $n(\%)$ & & \\
- HCC, $n(\%)$ & $82(46.3)$ & $80(45.2)$ \\
- ICC, $n(\%)$ & $6(3.4)$ & $11(6.2)$ \\
- Metastasis, $n(\%)$ & $89(50.3)$ & $86(48.6)$ \\
• Colorectal, $n(\%)$ & $52(65.8)$ & $47(61.8)$ \\
• Breast, $n(\%)$ & $5(6.3)$ & $3(3.9)$ \\
• Melanoma, $n(\%)$ & $7(8.9)$ & $4(5.3)$ \\
• Other, $n(\%)$ & $25(19)$ & $32(29)$ \\
Cirrhosis, $n(\%)$ & $68(38.4)$ & $66(37.3)$ \\
- Child A, $n(\%)$ & $60(88.0)$ & $54(81.1)$ \\
- Child B, $n(\%)$ & $7(11.1)$ & $11(16.8)$ \\
- Child C, $n(\%)$ & $1(0.9)$ & $1(2.1)$ \\
Tumor size, median (range) & $2.2 \mathrm{~cm}(0.5-10 \mathrm{~cm})$ & $2.0 \mathrm{~cm}(0.5-13 \mathrm{~cm})$ \\
Tumor number at beginning, $n$ (range) & $2(1-8)$ & $2(1-9)$ \\
Total treated tumors, median (range) & $1(1-4)$ & $2(1-20)$ \\
Ablations per patient, $n$ (range) & $1(1-4)$ & $1(1-10)$ \\
Patients receiving LTX, $n(\%)$ & $23(13.1)$ & $24(13.6)$ \\
\hline
\end{tabular}

SRFA stereotactic radiofrequency ablation, HCC hepatocellular carcinoma, ICC intrahepatic cholangiocarcinoma, Child Child-Pugh score, LTX liver transplantation, gr. group

\section{Statistical analysis}

The software R (version 3.5.2, R Foundation for Statistical Computing) and the $\mathrm{R}$ package MatchIt (1:1 matching with the nearest neighbor) were used for the propensity matching process to select patients for the control group.

The statistical analysis of comparisons was performed with the software IBM SPSS version 20 (IBM). Data were expressed as total numbers, median, and range. The overall survival and disease-free survival were evaluated using the Kaplan-Meier method and compared between the two groups with the log-rank test. The difference between categorical variables was evaluated with the $X^{2}$ test, and the difference between independent continuous variables was evaluated with the Mann-Whitney $U$ test. A $p$ value $<0.05$ was considered as with statistical significance.

\section{Results}

\section{Patient characteristics (Table 1)}

A total of 177 patients, 48 females and 129 males, with a median age of 65 years (7-87) underwent SRFA for treatment of subphrenic tumors in the hepatic dome. Diagnoses included $82(46.3 \%)$ HCCs, $6(3.4 \%)$ ICCs, and $89(50.3 \%)$ metastatic tumors. The majority $(65.8 \%)$ of metastatic disease originated from colorectal cancer. The median size of the 238 nodules was $2.2 \mathrm{~cm}(0.5-10 \mathrm{~cm})$. A median of 2 tumors $(1-11)$ were treated per ablation session (in total 204 sessions), including 111 patients $(62.7 \%)$ with additional tumors outside of the hepatic dome. At the beginning of the treatment, 76 patients had a solitary tumor in the liver, 49 had two tumors, 24 had three tumors, and 28 had more than three tumors (multiple nodules). Sixty-eight (38.4\%) patients suffered from underlying liver cirrhosis (60 (88\%) Child-Pugh A), and 23 (13.1\%) received a liver transplantation during follow-up. Forty-one patients underwent chemotherapy, 25 patients surgical resection, 9 patients TACE, and 6 patients conventional RF ablation prior to SRFA.

\section{Perioperative complications}

Perioperative major complications are shown in detail in Table 2. One death occurred following ablation of colorectal liver metastasis due to major bleeding (mortality rate $0.5 \%$ $(1 / 204))$. The total major complication rate was $12.3 \%$ (25 of 204). Three of these complications were clearly related to simultaneous thermal ablation of tumors in other locations, leading to a major complication rate of $10.7 \%$ (22 of 204) in hepatic dome tumors.

Thermal injuries of the diaphragm lead to a local defect in 2 cases that had to be surgically repaired. One patient developed liver failure after treatment of $2 \mathrm{HCCs}(5 \mathrm{~cm}$ and $3 \mathrm{~cm})$ requiring salvage liver transplantation. In one case, thermal injury of the bowel had to be surgically repaired. However, this 
Fig. 2 Case of a 70-year-old female with a $1.5-\mathrm{cm}$ colorectal cancer liver metastasis in segment VII in the hepatic dome. $\mathbf{a}, \mathbf{b}$ Portal venous phase initial CT scans with a hypo-enhancing nodule in segment VII (red dashed circle). c, d Axial native control CT and scout (d) with 3 coaxial needles in place (red arrowhead). e Fused CT image of the contrast-enhanced planning and final control CTs showing a complete coverage of the tumor (dark central nodule) by the coagulation zone (red arrowhead). $\mathbf{f}-\mathbf{h}$ The red dashed circle is marking the progressively shrinking coagulation zone at 3 months (f), 24 months (g), and 48 months (h) after SRFA
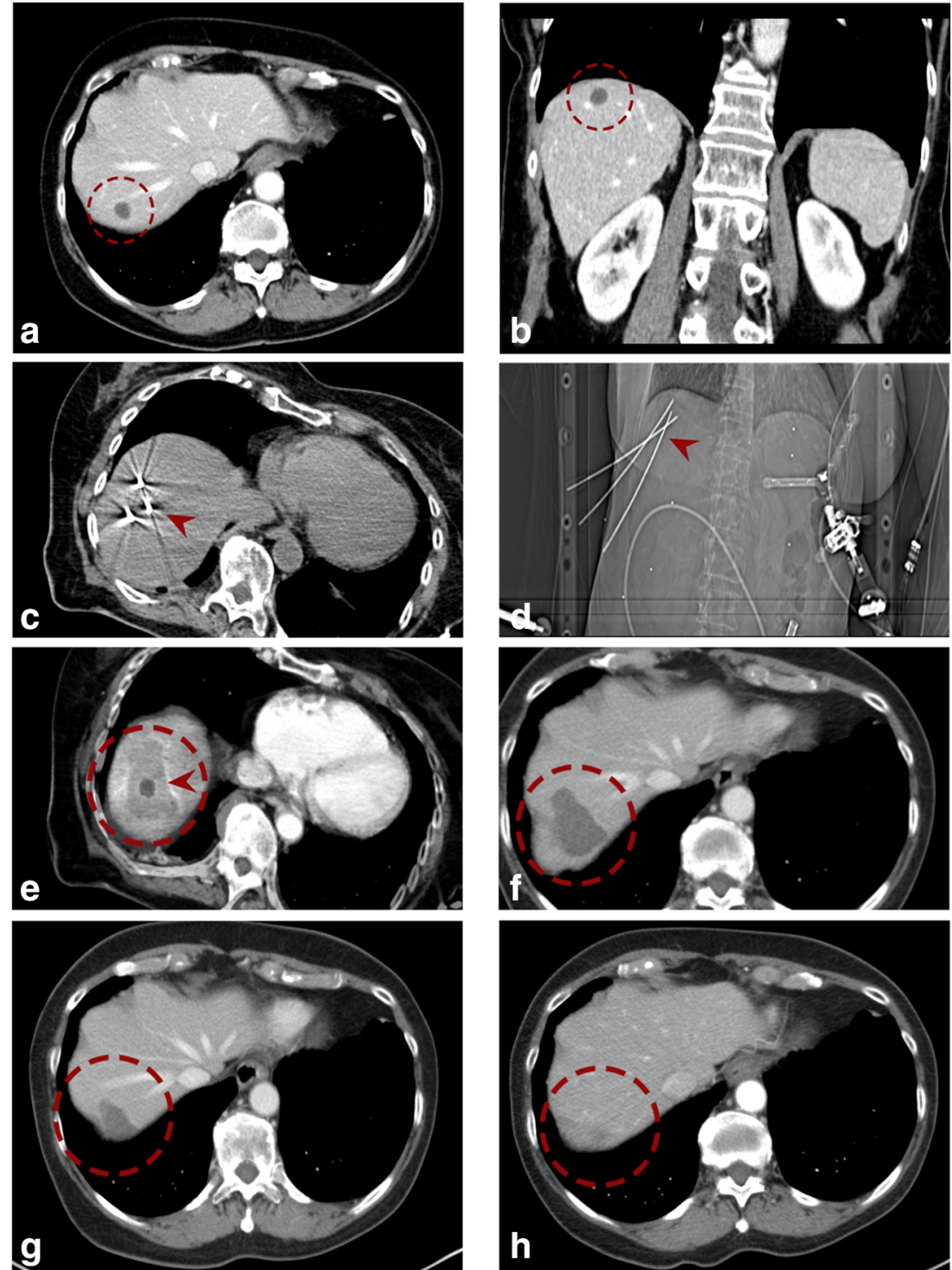

complication was related to simultaneous thermal ablation of an additional tumor in segment VI in the same session. Other complications included transient pulmonary failure with bilateral effusions (1 patient) pleural effusions requiring thoracenteses (5 patients).

A total of 14/25 (56\%) major complications were successfully treated by the interventional radiologist in the same anesthesia session by placing a thoracostomy tube in 5 patients with pneumothoraces and by transarterial embolization in nine patients with hepatic hemorrhages, respectively. Fever $\left(>37^{\circ} \mathrm{C}\right.$ ) and variably pronounced right shoulder pain (mainly mild) developed in all patients but subsided within a few days with symptomatic treatment. This is most likely related to thermal injury of the adjacent diaphragm and pleura. The median hospital stay after the ablation was 4 days, ranging from 1 to 28 days. There was no significant difference of major complication rate $(8.5 \%, 24 / 281 ; p=0.180)$ and hospital stay (median 4, 1-42 days; $p=0.301$ ) compared with the control group, respectively.

A subanalysis of the major complications in the hepatic dome group showed that the median number of applied RF probes and the median tumor size were significantly higher in ablation sessions with major complications (median 5 vs. 3 RF probes with $p=0.034$ and median size $3 \mathrm{~cm}$ vs. $2 \mathrm{~cm}$ with 0.023 , respectively).

\section{Technical success}

SRFA was successfully completed according to plan in all 238 tumors (technical success rate $100 \%$ ). A total of 232/238 tumors were successfully ablated at initial SRFA (97.5\% primary technical efficacy rate). Five tumors required retreatment, resulting in a secondary technical efficacy rate of $99.6 \%$ 
Fig. 3 Case of a 67-year-old male with a large $\mathrm{HCC}$ in the hepatic dome. a Arterial phase planning CT with a 9-cm HCC in segment IV/VIII (red dashed circle). b MIP of the control CT showing in total 12 inserted coaxial needles (red arrowhead). c, d Fused images from the navigation system with $3 \mathrm{D}$ views from arterial phase planning CT (a) and final control CT (d) with complete necrosis including a sufficient ablation margin. e, f Follow-up CT scans after 3 (e) and 24 months (f) with no evidence of local tumor recurrence (red dashed circle is marking the coagulation zone)
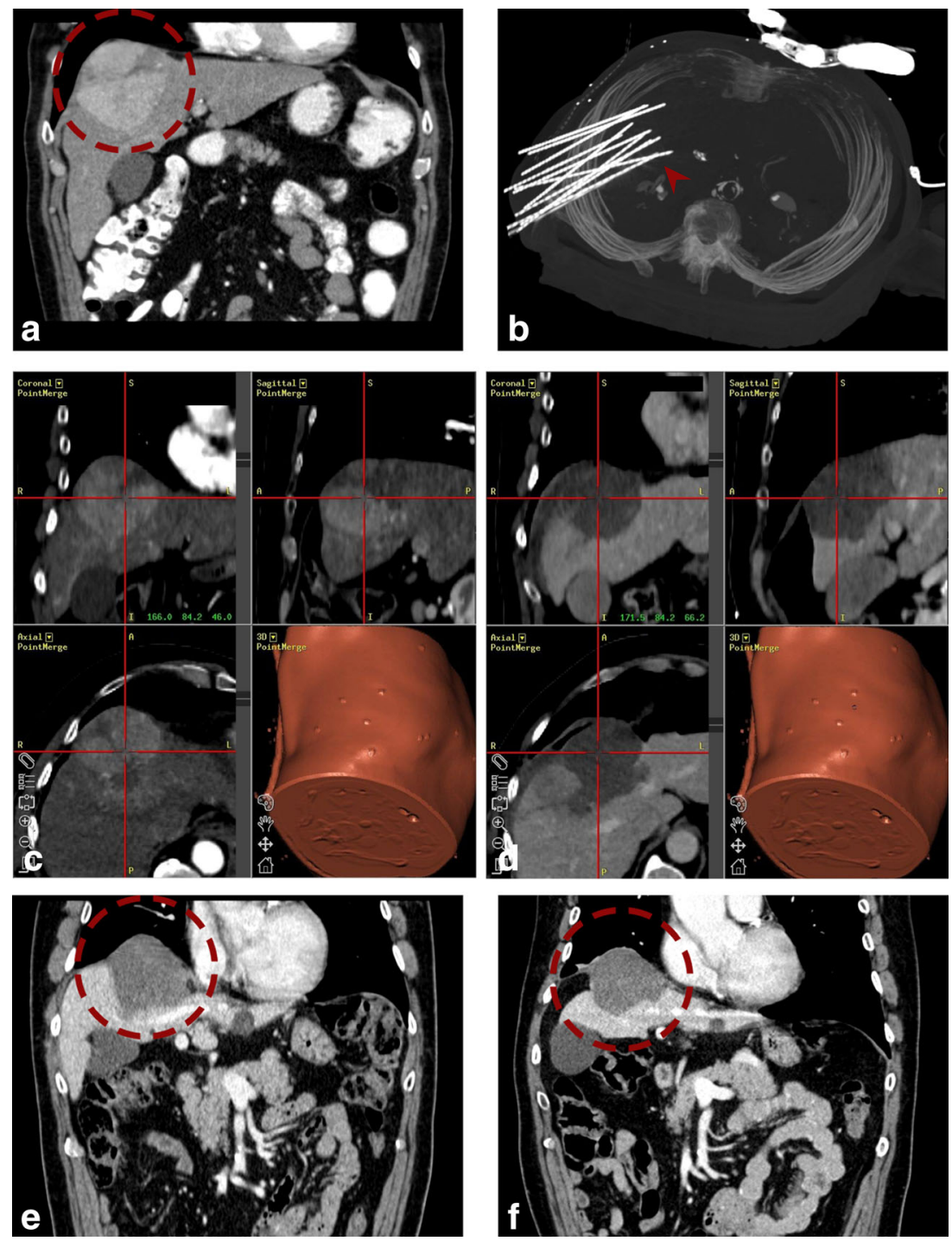

(Table 3). One to 20 (median 3) RF electrodes were inserted in each tumor.

Compared with the control group, there was no significant difference between primary and secondary efficacy $(96.8 \%$, 568/587, $p=0.608 ; 98.3 \%, 577 / 587, p=0.150)$.

In addition to SRFA, 3 patients received TACE and 8 patients received chemotherapy. Liver transplantation was performed in 23 patients where the histopathology examination revealed $2 \mathrm{LR}$.

\section{Local recurrence rate and distant recurrence}

Local tumor recurrence developed in 21 of 238 tumors $(8.8 \%$, Table 4, median imaging follow-up 12.6 months). Distant tumor recurrence in the liver was found in 84 patients $(47.5 \%)$, and extrahepatic metastasis in 23 patients (13\%), respectively. Of the 101 patients $(57 \%)$ experiencing intrahepatic recurrences, including four patients with local and distant recurrences, $82(81 \%)$ patients received repeated SRFA. Thirty-four $(41 \%)$ patients developed untreatable tumor progression.

The local recurrence rate of the control group was $7.2 \%$ (42/587). There was no significant difference compared with the hepatic dome group $(p=0.414)$.

\section{Overall and disease-free survival (Fig. 4)}

In patients with exclusively HCCs in the hepatic dome, the overall survival rates at 1,3 , and 5 years from the date of the first SRFA were $87.1 \%, 76.2 \%$, and $58.2 \%$ and $91 \%, 75.8 \%$, and $55.2 \%$ for matched controls, with a median overall survival (OS) of 66.9 months (95\% CI 50.4-84.7) and 72 months (95\% CI 36.6-142), respectively. The disease-free survival (DFS) for patients with exclusively HCCs in the hepatic dome after SRFA was $78 \%, 47.5 \%$, and $35.6 \%$, at 1,3 , and 5 years, respectively, with a median DFS of 19.2 months $(95 \%$ CI 
Table 2 Details of major complications after SRFA

\begin{tabular}{|c|c|c|c|c|c|c|c|c|c|c|}
\hline Patient & Age & Sex & $\begin{array}{l}\text { Primary } \\
\text { tumor }\end{array}$ & Cirr. & $\begin{array}{l}\text { Tumors/ } \\
\text { session }\end{array}$ & $\begin{array}{l}\text { Lesion size (max/ } \\
\text { session) }\end{array}$ & $\begin{array}{l}\text { Needles/ } \\
\text { session }\end{array}$ & Complication & Therapy & $\begin{array}{l}\text { Related to } \\
\text { H.D. }\end{array}$ \\
\hline 1 & 53 & Male & $\mathrm{HCC}$ & Yes & 2 & $5.0 \mathrm{~cm},(5.0 \mathrm{~cm})$ & 16 & Liver failure & Acute LTX & Yes \\
\hline 2 & 48 & Male & $\mathrm{HCC}$ & No & 1 & $6.4 \mathrm{~cm},(6.4)$ & 12 & ARDS, pleural effusion & ICU, drainage & Yes \\
\hline 3 & 73 & Female & $\mathrm{HCC}$ & Yes & 1 & $1.1 \mathrm{~cm}$ & 3 & Diaphragmatic defect & Surgery & Yes \\
\hline 4 & 47 & Male & NET & No & 2 & $3.5 \mathrm{~cm},(3.5)$ & 6 & Diaphragmatic hernia & Surgery & Yes \\
\hline 5 & 68 & Female & OVC & No & 2 & $2.8 \mathrm{~cm},(2.8)$ & 6 & Bowel thermal damage & Surgery & No \\
\hline 6 & 77 & Male & CRC & No & 3 & $5.5 \mathrm{~cm},(5.5)$ & 12 & $\begin{array}{l}\text { Perihepatic bleeding, hemorrhagic } \\
\text { shock w. death }\end{array}$ & $\begin{array}{l}\text { AG-coiling, } \\
\text { ICU }\end{array}$ & Yes \\
\hline 7 & 69 & Male & CRC & No & 1 & $7.2 \mathrm{~cm}$ & 10 & Pneumothorax & Chest-tube & Yes \\
\hline 8 & 61 & Male & CRC & No & 2 & $4.0 \mathrm{~cm},(4.0)$ & 8 & Pneumothorax & Chest-tube & Yes \\
\hline 9 & 61 & Female & $\mathrm{CRC}$ & No & 5 & $5.0 \mathrm{~cm},(5.0)$ & 22 & Pneumothorax & Chest-tube & Yes \\
\hline 10 & 70 & Male & $\mathrm{HCC}$ & Yes & 1 & $7.0 \mathrm{~cm}$ & 9 & Pneumothorax & Chest-tube & Yes \\
\hline 11 & 69 & Male & $\mathrm{HCC}$ & Yes & 3 & $4.0 \mathrm{~cm},(4.0)$ & 14 & Pneumothorax & Chest-tube & Yes \\
\hline 12 & 38 & Male & CRC & No & 5 & $1.0 \mathrm{~cm}$ & 14 & Perihepatic bleeding & AG-coiling & No \\
\hline 13 & 72 & Male & ESC & No & 1 & $1.5 \mathrm{~cm}$ & 5 & Perihepatic bleeding & AG-coiling & Yes \\
\hline 14 & 51 & Male & $\mathrm{HCC}$ & Yes & 1 & $1.5 \mathrm{~cm}$ & 3 & Perihepatic bleeding & AG-coiling & Yes \\
\hline 15 & 72 & Male & $\mathrm{CRC}$ & No & 4 & $2.0 \mathrm{~cm},(2.1)$ & 15 & Perihepatic bleeding & AG-coiling & Yes \\
\hline 16 & 46 & Female & OVC & No & 2 & $3.0,(3.0)$ & 7 & Perihepatic bleeding & AG-coiling & Yes \\
\hline 17 & 63 & Male & $\mathrm{HCC}$ & Yes & 2 & $2.0 \mathrm{~cm},(2.7)$ & 4 & Intrahepatic bleeding & AG-coiling & Yes \\
\hline 18 & 63 & Male & $\mathrm{HCC}$ & Yes & 1 & $2.2 \mathrm{~cm}$ & 3 & Perihepatic bleeding & AG-coiling & Yes \\
\hline 19 & 48 & Male & $\mathrm{HCC}$ & No & 3 & $2.0 \mathrm{~cm},(3.0)$ & 9 & Perihepatic bleeding & AG-coiling & No \\
\hline 20 & 7 & Female & NBL & No & 1 & $3.5 \mathrm{~cm}$ & 6 & Intrahepatic bleeding & AG-coiling & Yes \\
\hline 21 & 67 & Male & $\mathrm{HCC}$ & Yes & 2 & $1.6 \mathrm{~cm},(1,8 \mathrm{~cm})$ & 6 & Pleural effusion & ICU, drainage & Yes \\
\hline 22 & 56 & Male & $\mathrm{HCC}$ & Yes & 3 & $2.8 \mathrm{~cm}(2.8 \mathrm{~cm})$ & 10 & Pleural effusion & $\begin{array}{l}\text { Drainage } \\
\quad \text { (US-guided) }\end{array}$ & Yes \\
\hline 23 & 60 & Male & CRC & No & 1 & $3.0 \mathrm{~cm}$ & 10 & Pleural effusion & $\begin{array}{l}\text { Drainage } \\
\quad \text { (US-guided) }\end{array}$ & Yes \\
\hline 24 & 68 & Male & MEL & No & 1 & $5.5 \mathrm{~cm}$ & 8 & Pleural effusion & $\begin{array}{l}\text { Drainage } \\
\quad \text { (US-guided) }\end{array}$ & Yes \\
\hline 25 & 58 & Male & $\mathrm{HCC}$ & Yes & 2 & $8.5 \mathrm{~cm},(8.5)$ & 18 & Pleural effusion & $\begin{array}{l}\text { Drainage } \\
\quad \text { (US-guided) }\end{array}$ & Yes \\
\hline
\end{tabular}

SRFA stereotactic radiofrequency ablation, $H C C$ hepatocellular carcinoma, $C R C$ colorectal carcinoma, $M E L$ melanoma, $N B L$ neuroblastoma, $N E T$ neuroendrocrine tumor, $O V C$ ovarian cancer, ESC esophageal cancer, Cirr hepatic cirrhosis, ICU intensive care unit, $A G$ angiography, LTX liver transplantation, H.D. hepatic dome

16.6-52.9) and for matched controls $67.2 \%, 50.8 \%$, and $35.5 \%$, with a median DFS of 36.6 months (95\% CI $12.1-$ 53.8), respectively.

In terms of OS and DFS, there was no significant difference between the control and hepatic dome groups, with $p=0.804$ and $p=0.757$, respectively.

\section{Discussion}

This retrospective analysis with a propensity score-matched control cohort suggests that SRFA of subphrenic tumors can be accomplished with comparable safety and efficacy rates achieved for tumors treated elsewhere in the liver. The technical success rate, i.e., completion according to plan, in our study was $100 \%$, which is in line with reports from the literature $[5,18]$. The primary technical efficacy was $97.5 \%$, also comparable with reported primary technical efficacy rates after conventional RF ablation in the hepatic dome ranging from $86.7 \%$ [5] to $93.2-96 \%[19,20]$. The conventionally treated tumors were smaller (median diameter $1.7 \mathrm{~cm}$ and maximal diameter $4 \mathrm{~cm}$ ) compared with our study with a median tumor size of $2.2 \mathrm{~cm}$ and a maximal diameter of $10 \mathrm{~cm}$. We observed local tumor progression in $21(8.8 \%)$ of 238 tumors, with no significant difference in local tumor treatment outcomes compared with the control group $(p=0.414)$. Kim et al [5] reported local tumor progression in $13.3 \%$ after RF ablation of subdiaphragmatic HCCs with a transthoracic approach despite the inclusion of smaller lesions. Cha et al [21] compared the therapeutic outcomes of conventional US-guided RF ablation for subcardiac and non-subcardiac HCCs in 73 patients and reported no significant difference 
Table 3 Tumor-based therapy success rates compared with control group

\begin{tabular}{lccc}
\hline Rate & Hepatic dome gr. & Control gr. & $p$ value \\
\hline Technical success, $n(\%)$ & $238 / 238(100)$ & $587 / 587(100)$ & N/A \\
Primary technical efficacy, $n(\%)$ & $232 / 238(97.5)$ & $568 / 587(96.8)$ & 0.608 \\
Secondary technical efficacy, $n(\%)$ & $237 / 238(99.6)$ & $577 / 587(98.3)$ & 0.150 \\
Local recurrence, $n(\%)$ & $21 / 238(8.8)$ & $42 / 587(7.2)$ & 0.414 \\
\hline
\end{tabular}

gr. group

observed between both groups, with a cumulative local tumor progression rate $>15 \%$ in the subcardiac group. Recently, Vo Chieu et al [18] showed local tumor progression rates of up to $13.6 \%$ in the "risk group" after microwave ablation of tumors abutting the diaphragm. Microwave ablation (MWA) generally requires fewer overlapping ablations compared with RFA. Asvadi et al [22] treated 48 hepatic dome lesions in 46 patients with conventional CT-guided MWA and reported a complete response rate of $94 \%$. Transarterial chemoembolization (TACE) is the recommended locoregional treatment for patients with intermediate HCC $[23,24]$. Several studies reported the feasibility and benefit of RF ablation after transarterial embolization with complete response rates of $76-82 \%$ in large HCC $[25,26]$. We attribute the good local tumor control after SRFA to consistent achievement of a sufficient safety margin of at least $5 \mathrm{~mm}$ [3]. SRFA offers three-dimensional ablation planning to achieve optimal alignment of RF probes to create multiple overlapping coagulation volumes. Usage of an aiming device facilitates very precise path alignment and targeting [14]. In case of poor tumor visibility, SRFA planning may include fusion with previously acquired MR images. Temporary disconnection of the endotracheal tube facilitates good control of respiratory motion [27]. Immediate postablation contrast-enhanced CT fusion with the planning CT allows for rapid reliable judgment of the ablation results with the option for re-ablation. Bale et al [28] achieved complete pathological response after SRFA (i.e. no evidence of tumor) with these techniques in 183 of 188 (97.3\%) hepatocellular carcinomas with a median size of $2.5 \mathrm{~cm}$ (range, 1-8) in a histopathological study in explanted livers.

The major complication rate in our study was $12.3 \%$, slightly but not significantly higher than the $8.8 \%$ rate in the control group with random non-subdiaphragmatic tumors. The majority of complications such as pleural effusion or pneumothoraces were relatively easy to treat. Significant bleeding in all but one instance could be immediately managed with angiographic coiling in the same general anesthesia session. Rhim et al [29] reported a low complication rate of $4 \%(1 / 25)$ with artificial ascites during RF ablation of subdiaphragmatic tumors, and Kim et al [5] described no major complications in a small series of 15 patients treated by RF ablation with an angulated transhepatic approach. More recently, Vo Chieu et al [18] reported major complication rates of up to $57.9 \%$ with microwave ablation in subcapsular hepatic dome tumors with a transpleural approach while Ding et al [20] reported major complication rate of $10 \%(6 / 60)$ with a transhepatic approach. Asvadi et al [22] showed that creation of artificial ascites is a valuable option for avoiding diaphragm-associated complications. Application of this technique would have most likely prevented most of the complications related to thermal injury of the diaphragm in our patient series. In unresectable HCCs, Zhang et al (16) reported a major complication rate of $4.4 \%$ after combined TACE-RF and Zhao et al (19) of $2.3 \%$ after TACE and $9.4 \%$ after RF ablation, respectively. The complication rate of our study is moderately higher, which may be due in part to the larger size of our treated tumors and the larger number of inserted needles (median 9 needles, ranging from 3 to 22). Supporting this assumption, a subanalysis of our data showed that the complication rate in larger tumors treated with more RF probes was significantly higher. However, the major complication rate of the present study compares favorably with the reported rates following laparoscopic or open liver resection of primary or metastatic liver tumors in the posterosuperior segments of the liver. According to the in-surgical studies that primarily used Clavien-Dindo classification [30], the major complicate rate in the present study was $4.9 \%$ (10/204). Major complication rates after laparoscopic RFA were $10 \%$ and $12.4 \%$, respectively $[20,31]$. Several surgical studies report significantly higher major complicate rates of $10-27 \%$ after LLR, and $18-37 \%$ after open resection, respectively [10, 32-35].

Overall survival rates after SRFA of colorectal liver metastases [16], breast cancer liver metastases [36], intrahepatic cholangiocellular carcinomas [37], and melanoma liver metastases [38] are comparable with those of liver resection. In the current study, patients with exclusively hepatic dome HCCs showed OS rates at 1,3, and 5 years from the date of the first SRFA of $87.1 \%, 76.2 \%$, and $58.2 \%$ and $91 \%, 75.8 \%$, and $55.2 \%$ for matched controls. The median OS rates were 66.9 months and 72 months, respectively. Ding et al [20] treated 60 patients with HCC with percutaneous RFA and 56 patients with laparoscopic RFA. The OS rates for the percutaneous RF ablation group were $91.7 \%, 56.7 \%$, and 36.7 at 1,3 , and 5 years with a median OS of 44 months. The corresponding rates for the laparoscopic RF ablation group were $89.2 \%, 57.1 \%$, and 44.6 at 1 , 3 , and 5 years with a median of 57 months, respectively. Kim et al [39] reported high 3- and 5-year OS rates of $84 \%$ and $72.7 \%$ in HCC patients with $12 \%$ of tumors 
Table 4 Unsuccessful local tumor control after SRFA

\begin{tabular}{|c|c|c|c|c|c|c|c|c|c|}
\hline Patient & Age & Sex & Tumor & Cirr. & $\begin{array}{l}\text { Tumor } \\
\text { size }\end{array}$ & $\begin{array}{l}N \\
\text { needles }\end{array}$ & $\begin{array}{l}\text { Ablation } \\
\text { time }\end{array}$ & $\begin{array}{l}\text { Unsuccessful } \\
\text { Pretherapy }\end{array}$ & Outcome \\
\hline 1 & 65 & Male & $\mathrm{HCC}$ & Yes & $7.0 \mathrm{~cm}$ & 5 & $32 \mathrm{~min}$ & No & LR \\
\hline 2 & 74 & Male & $\mathrm{HCC}$ & No & $7.0 \mathrm{~cm}$ & 8 & $72 \mathrm{~min}$ & No & LR \\
\hline 3 & 75 & Male & ICC & No & $6.0 \mathrm{~cm}$ & 5 & $34 \mathrm{~min}$ & No & LR \\
\hline 4 & 54 & Male & $\mathrm{CRC}$ & No & $10.0 \mathrm{~cm}$ & 10 & $112 \mathrm{~min}$ & No & LR \\
\hline 5 & 38 & Male & $\mathrm{CRC}$ & No & $1.0 \mathrm{~cm}$ & 1 & $12 \mathrm{~min}$ & SRFA & LR \\
\hline 6 & 57 & Male & $\mathrm{HCC}$ & Yes & $2.6 \mathrm{~cm}$ & 3 & $16 \mathrm{~min}$ & No & LR \\
\hline 7 & 69 & Male & $\mathrm{HCC}$ & Yes & $2.0 \mathrm{~cm}$ & 3 & $16 \mathrm{~min}$ & No & LR \\
\hline 8 & 69 & Male & $\mathrm{HCC}$ & Yes & $1.0 \mathrm{~cm}$ & 1 & $12 \mathrm{~min}$ & No & LR \\
\hline 8 & 69 & Male & $\mathrm{HCC}$ & Yes & $1.0 \mathrm{~cm}$ & 1 & $12 \mathrm{~min}$ & SRFA & LR \\
\hline 9 & 60 & Male & $\mathrm{HCC}$ & Yes & $2.8 \mathrm{~cm}$ & 3 & $16 \mathrm{~min}$ & No & LR \\
\hline 10 & 66 & Female & $\mathrm{HCC}$ & Yes & $4.5 \mathrm{~cm}$ & 8 & $66 \mathrm{~min}$ & No & LR \\
\hline 11 & 48 & Male & $\mathrm{HCC}$ & No & $6.4 \mathrm{~cm}$ & 12 & $128 \mathrm{~min}$ & No & LR \\
\hline 11 & 48 & Male & $\mathrm{HCC}$ & No & $5.0 \mathrm{~cm}$ & 9 & $64 \mathrm{~min}$ & SRFA & LR \\
\hline 12 & 69 & Male & $\mathrm{HCC}$ & Yes & $5.0 \mathrm{~cm}$ & 9 & $96 \mathrm{~min}$ & TACE & LR \\
\hline 13 & 61 & Male & $\mathrm{CRC}$ & No & $4.0 \mathrm{~cm}$ & 5 & $29 \mathrm{~min}$ & No & LR \\
\hline 13 & 61 & Male & $\mathrm{CRC}$ & No & $2.5 \mathrm{~cm}$ & 5 & $26 \mathrm{~min}$ & SRFA & LR \\
\hline 14 & 68 & Male & MEL & No & $5.5 \mathrm{~cm}$ & 8 & $36 \mathrm{~min}$ & No & LR \\
\hline 15 & 73 & Male & $\mathrm{HCC}$ & Yes & $5.0 \mathrm{~cm}$ & 9 & $39 \mathrm{~min}$ & No & LR \\
\hline 16 & 47 & Male & NET & No & $3.5 \mathrm{~cm}$ & 3 & $32 \mathrm{~min}$ & No & LR \\
\hline 16 & 47 & Male & NET & No & $2.0 \mathrm{~cm}$ & 2 & $24 \mathrm{~min}$ & No & LR \\
\hline 17 & 55 & Female & OVC & No & $2.5 \mathrm{~cm}$ & 4 & $32 \mathrm{~min}$ & No & LR \\
\hline 18 & 68 & Male & $\mathrm{RCC}$ & No & $1.0 \mathrm{~cm}$ & 3 & $12 \mathrm{~min}$ & No & IN \\
\hline 19 & 65 & Male & $\mathrm{HCC}$ & Yes & $1.3 \mathrm{~cm}$ & 2 & $12 \mathrm{~min}$ & No & IN \\
\hline 20 & 49 & Male & CRC & No & $2.3 \mathrm{~cm}$ & 2 & $12 \mathrm{~min}$ & No & IN \\
\hline 5 & 38 & Male & $\mathrm{CRC}$ & No & $2.0 \mathrm{~cm}$ & 1 & $12 \mathrm{~min}$ & No & IN \\
\hline 21 & 58 & Male & CRC & No & $7.0 \mathrm{~cm}$ & 9 & $66 \mathrm{~min}$ & No & IN \\
\hline 21 & 58 & Male & CRC & No & $5.0 \mathrm{~cm}$ & 7 & $52 \mathrm{~min}$ & No & IN \\
\hline
\end{tabular}

SRFA stereotactic radiofrequency ablation, HCC hepatocellular carcinoma, $C R C$ colorectal carcinoma, ICC intrahepatic cholangiocarcinoma, $M E L$ melanoma, NET neuroendocrine tumor, $O V C$ ovarian cancer, $R C C$ renal cell cancer, Cirr. hepatic cirrhosis, IN incomplete necrosis, $L R$ local recurrence, TACE transcatheter arterial chemoembolization

abutting the diaphragm with a mean tumor size of $2.1 \mathrm{~cm}$. Llovet et al [40] showed in a RCT the survival benefit of TACE vs. a control group with significantly higher 1- and 2year OS of $82 \%$ and $63 \%$ vs. $63 \%$ and $27 \%$, respectively. Especially in larger tumors, several studies reported evidence for the benefit of a combination therapy of TACE and RF ablation; Zhang et al [26] reported 1-, 2-, and 3 -year OS rates of $89 \%, 61 \%$, and $43 \%$ after combined RF ablation and TACE in patients with HCC beyond the Milan criteria.
Fig. 4 Overall and disease-free survival after initial SRFA of patients with exclusive HCCs in the hepatic dome in comparison with their matched controls
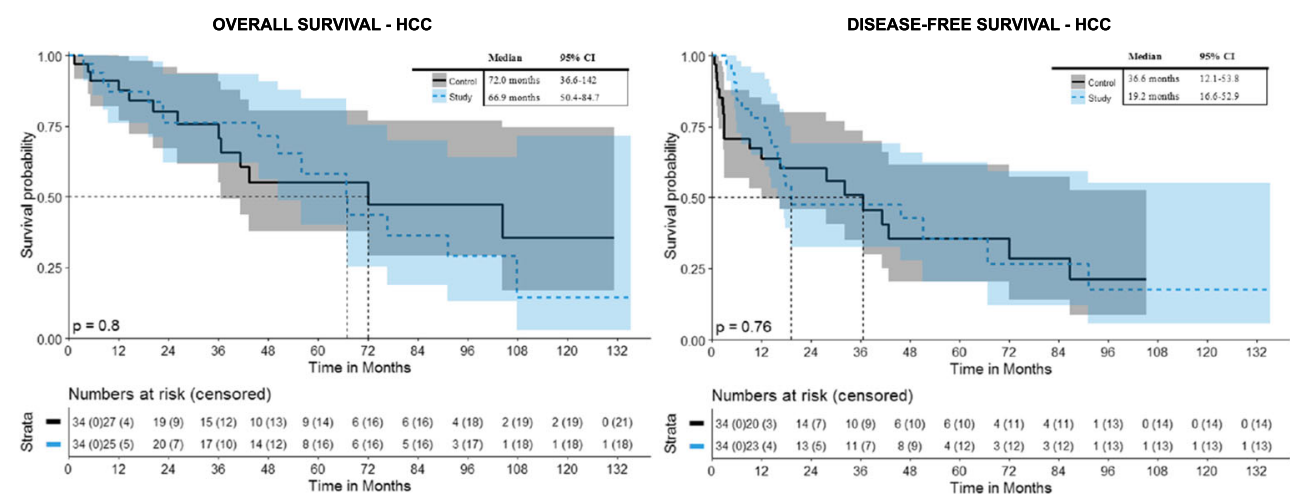
The DFS for patients with exclusively hepatic dome HCC was $78 \%, 47.5 \%$, and $35.6 \%$ at 1,3 , and 5 years and for matched controls $67.2 \%, 50.8 \%$, and $35.5 \%$, respectively. These data compare with Kim et al [39], who reported similar recurrence-free survival rates after RF ablation of $66.5 \%$, $20.4 \%$, and $17 \%$ at 1,3 , and 5 years.

\section{Limitations}

Study limitations include the retrospective design, heterogeneity of treatments (adjunctive TACE or chemotherapy), and single-center treatment bias. Comparisons with previous related studies are limited as stereotactic navigation systems were not employed in prior reports.

In conclusion, stereotactic RFA is a feasible, safe, and efficacious option in the management of difficult-to-treat hepatic tumors abutting the diaphragm.

Funding Open access funding provided by University of Innsbruck and Medical University of Innsbruck. The authors state that this work has not received any funding.

\section{Compliance with ethical standards}

Guarantor The scientific guarantor of this publication is Reto Bale.

Conflict of interest Prof. Bale is a consultant for CAScination and i-Sys Medizintechnik.

All other authors of this manuscript declare no relationships with any companies, whose products or services may be related to the subject matter of the article.

Statistics and biometry Two of the authors (PS, EL) have significant statistical expertise.

Informed consent Written informed consent was obtained from all subjects (patients) in this study.

Ethical approval Institutional Review Board approval was obtained.

Methodology
- retrospective
- case-control study
- performed at one institution

Open Access This article is distributed under the terms of the Creative Commons Attribution 4.0 International License (http:// creativecommons.org/licenses/by/4.0/), which permits unrestricted use, distribution, and reproduction in any medium, provided you give appropriate credit to the original author(s) and the source, provide a link to the Creative Commons license, and indicate if changes were made.

\section{References}

1. European Association For The Study Of The Liver, European Organisation For Research And Treatment Of Cancer (2012)
EASL-EORTC clinical practice guidelines: management of hepatocellular carcinoma. J Hepatol 56:908-943

2. Ahmed M, Solbiati L, Brace CL et al (2014) Image-guided tumor ablation: standardization of terminology and reporting criteria-a 10-year update. Radiology 273:241-260

3. Kim YS, Lee WJ, Rhim H, Lim HK, Choi D, Lee JY (2010) The minimal ablative margin of radiofrequency ablation of hepatocellular carcinoma ( $>2$ and $<5 \mathrm{~cm}$ ) needed to prevent local tumor progression: 3D quantitative assessment using CT image fusion. AJR Am J Roentgenol 195:758-765

4. Head HW, Dodd GD 3rd, Dalrymple NC et al (2007) Percutaneous radiofrequency ablation of hepatic tumors against the diaphragm: frequency of diaphragmatic injury. Radiology 243:877-884

5. Kim YK, Kim CS, Lee JM, Chung GH, Chon SB (2006) Efficacy and safety of radiofrequency ablation of hepatocellular carcinoma in the hepatic dome with the CT-guided extrathoracic transhepatic approach. Eur J Radiol 60:100-107

6. Park BJ, Byun JH, Jin YH et al (2009) CT-guided radiofrequency ablation for hepatocellular carcinomas that were undetectable at US: therapeutic effectiveness and safety. J Vasc Interv Radiol 20: 490-499

7. Shibata T, Maetani Y, Kubo T, Itoh K, Togashi K, Hiraoka M (2004) Transthoracic percutaneous radiofrequency ablation for liver tumors in the hepatic dome. J Vasc Interv Radiol 15:1323-1327

8. Toyoda M, Kakizaki S, Horiuchi K et al (2006) Computed tomography-guided transpulmonary radiofrequency ablation for hepatocellular carcinoma located in hepatic dome. World $\mathrm{J}$ Gastroenterol 12:608-611

9. Song I, Rhim H, Lim HK, Kim YS, Choi D (2009) Percutaneous radiofrequency ablation of hepatocellular carcinoma abutting the diaphragm and gastrointestinal tracts with the use of artificial ascites: safety and technical efficacy in 143 patients. Eur Radiol 19: 2630-2640

10. Cho JY, Han HS, Yoon YS, Shin SH (2008) Feasibility of laparoscopic liver resection for tumors located in the posterosuperior segments of the liver, with a special reference to overcoming current limitations on tumor location. Surgery 144:32-38

11. Hori T, Nagata K, Hasuike $S$ et al (2003) Risk factors for the local recurrence of hepatocellular carcinoma after a single session of percutaneous radiofrequency ablation. J Gastroenterol 38:977-981

12. Shirai K, Tamai H, Shingaki $\mathrm{N}$ et al (2011) Clinical features and risk factors of extrahepatic seeding after percutaneous radiofrequency ablation for hepatocellular carcinoma. Hepatol Res 41:738-745

13. Teratani T, Yoshida H, Shiina S et al (2006) Radiofrequency ablation for hepatocellular carcinoma in so-called high-risk locations. Hepatology 43:1101-1108

14. Widmann G, Schullian P, Haidu M, Fasser M, Bale R (2011) Targeting accuracy of CT-guided stereotaxy for radiofrequency ablation of liver tumours. Minim Invasive Ther Allied Technol 20: 218-225

15. Bale R, Widmann G, Haidu M (2011) Stereotactic radiofrequency ablation. Cardiovasc Intervent Radiol 34:852-856

16. Bale R, Widmann G, Schullian P et al (2012) Percutaneous stereotactic radiofrequency ablation of colorectal liver metastases. Eur Radiol 22:930-937

17. Omary RA, Bettmann MA, Cardella JF et al (2003) Quality improvement guidelines for the reporting and archiving of interventional radiology procedures. J Vasc Interv Radiol 14:S293-S295

18. Vo Chieu VD, Werncke T, Hensen B, Wacker F, Ringe KI (2018) CT-guided microwave ablation of liver tumors in anatomically challenging locations. Cardiovasc Intervent Radiol 41:1520-1529

19. Rhim H, Lim HK (2009) Radiofrequency ablation for hepatocellular carcinoma abutting the diaphragm: the value of artificial ascites. Abdom Imaging 34:371-380

20. Tu JF, Ding YH, Chen L et al (2017) Iodine-125 brachytherapy prophylaxis after radiofrequency ablation cannot benefit patients 
in high risk of locoregional hepatocellular carcinoma recurrence. Sci Rep 7:3689

21. Cha DI, Kang TW, Song KD et al (2018) Radiofrequency ablation for subcardiac hepatocellular carcinoma: therapeutic outcomes and risk factors for technical failure. Eur Radiol. https://doi.org/10. 1007/s00330-018-5868-2

22. Asvadi NH, Anvari A, Uppot RN, Thabet A, Zhu AX, Arellano RS (2016) CT-guided percutaneous microwave ablation of tumors in the hepatic dome: assessment of efficacy and safety. J Vasc Interv Radiol 27:496-502 quiz 503

23. Lopez PM, Villanueva A, Llovet JM (2006) Systematic review: evidence-based management of hepatocellular carcinoma-an updated analysis of randomized controlled trials. Aliment Pharmacol Ther 23:1535-1547

24. Kitai S, Kudo M, Minami Y et al (2008) A new prognostic staging system for hepatocellular carcinoma: value of the biomarker combined Japan integrated staging score. Intervirology 51(Suppl 1):8694

25. Lencioni R, Cioni D, Donati F, Bartolozzi C (2001) Combination of interventional therapies in hepatocellular carcinoma. Hepatogastroenterology 48:8-14

26. Zhang L, Yin X, Gan YH et al (2014) Radiofrequency ablation following first-line transarterial chemoembolization for patients with unresectable hepatocellular carcinoma beyond the Milan criteria. BMC Gastroenterol 14:11

27. Widmann G, Schullian P, Haidu M, Wiedermann FJ, Bale R (2010) Respiratory motion control for stereotactic and robotic liver interventions. Int J Med Robot 6:343-349

28. Bale R, Schullian P, Eberle G et al (2018) Stereotactic radiofrequency ablation of hepatocellular carcinoma - a histopathological study in explanted livers. Hepatology. https://doi.org/10.1002/hep.30406

29. Rhim H, Lim HK, Kim YS, Choi D (2008) Percutaneous radiofrequency ablation with artificial ascites for hepatocellular carcinoma in the hepatic dome: initial experience. AJR Am J Roentgenol 190: 91-98

30. Dindo D, Demartines N, Clavien PA (2004) Classification of surgical complications: a new proposal with evaluation in a cohort of 6336 patients and results of a survey. Ann Surg 240:205-213
31. Mulier S, Mulier P, Ni Y et al (2002) Complications of radiofrequency coagulation of liver tumours. Br J Surg 89:1206-1222

32. Kaneko H, Takagi S, Otsuka Y et al (2005) Laparoscopic liver resection of hepatocellular carcinoma. Am J Surg 189:190-194

33. D'Hondt M, Tamby E, Boscart I et al (2018) Laparoscopic versus open parenchymal preserving liver resections in the posterosuperior segments: a case-matched study. Surg Endosc 32:1478-1485

34. Castaing D, Vibert E, Ricca L, Azoulay D, Adam R, Gayet B (2009) Oncologic results of laparoscopic versus open hepatectomy for colorectal liver metastases in two specialized centers. Ann Surg 250:849-855

35. Xiao L, Xiang LJ, Li JW, Chen J, Fan YD, Zheng SG (2015) Laparoscopic versus open liver resection for hepatocellular carcinoma in posterosuperior segments. Surg Endosc 29:2994-3001

36. Bale R, Richter M, Dünser M, Levy E, Buchberger W, Schullian P (2018) Stereotactic radiofrequency ablation for breast cancer liver metastases. J Vasc Interv Radiol 29:262-267

37. Haidu M, Dobrozemsky G, Schullian P et al (2012) Stereotactic radiofrequency ablation of unresectable intrahepatic cholangiocarcinomas: a retrospective study. Cardiovasc Intervent Radiol 35:1074-1082

38. Bale R, Schullian P, Schmuth M, Widmann G, Jaschke W, Weinlich $G$ (2016) Stereotactic radiofrequency ablation for metastatic melanoma to the liver. Cardiovasc Intervent Radiol 39:1128-1135

39. Kim SS, Kang TW, Kim M et al (2018) Initial radiofrequency ablation failure for hepatocellular carcinoma: repeated radiofrequency ablation versus transarterial chemoembolisation. Clin Radiol 73:216 e211-216 e218

40. Llovet JM, Real MI, Montaña X et al (2002) Arterial embolisation or chemoembolisation versus symptomatic treatment in patients with unresectable hepatocellular carcinoma: a randomised controlled trial. Lancet 359:1734-1739

Publisher's note Springer Nature remains neutral with regard to jurisdictional claims in published maps and institutional affiliations. 